\title{
DSL PHOTOETCHING: PRINCIPLES AND APPLICATION TO STUDY NATURE OF DEFECTS IN III-V MATERIALS
}

\author{
J.L. WEYHER \\ MASPEC-C.N.R. Institute, Via Chiavari 18/A, 43100 Parma, Italy
}

\begin{abstract}
After a short general description of the chemical etching of semiconductors the mechanisms of defect-selective etching are described in detail. Two distinct mechanisms that lead to the formation of etch pits and etch hillocks on dislocations emerging at a semiconductor surface are discussed. The principles of the formation of defect-related etch features are described for the $\mathrm{HF}-\mathrm{CrO}_{3}-\mathrm{H}_{2} \mathrm{O}$ etching system used for etching of $\mathrm{GaAs}$. A model of surface reactions is presented and the influence of illumination during etching on the defect-selectivity is emphasized. The use of ultra sensitive photoetching to study the nature and origin of complex defects in SI and $n$-type GaAs is documented. In particular, the concept for the formation of dislocation cell structure in undoped $\mathrm{GaAs}$ is presented and the ability of photoetching to reveal the structural changes during annealing is visualized.
\end{abstract}

PACS numbers: $81.60 . \mathrm{Cp}, 61.70 . \mathrm{Jc}, 61.70 . \mathrm{At}$

\section{Introduction}

Chemical etching plays an important role in the technology of semiconductors. It is used both for the preparation of surfaces of substrates (polishing), profile or pattern etching and for the structural characterization of materials, i.e. revealing of crystallographic and chemical inhomogeneities. There are two main categories of wet chemical etching depending on the rate limiting step of surface reactions. Processes where the diffusion of reactants towards the surface is the rate limiting factor belong to the first category. The overall etch rate is in this case determined by Fick's first law of diffusion. The second category covers selective etching (called also defect revealing) where selectivity refers to the local differences in the etch rate on structural defects or chemical inhomogeneities. The rate of etching depends here upon chemical activity of the semiconductor surface in the etching medium, 
i.e. the process is activation (kinetically) controlled. The simplest way to visualize these two different processes of etching is to record the rate of etching across the partially masked semiconductor surface. As a result of a diffusion limited etching in a non-stirred solution an increased etch rate at the mask edge is observed (trenching or negative crown effect), while an ideal kinetically controlled process yields flat-bottomed profiles with local variations of the etch rate on defects (D), as illustrated in Fig. 1(a) and 1(b), respectively. A good defect selective etchant

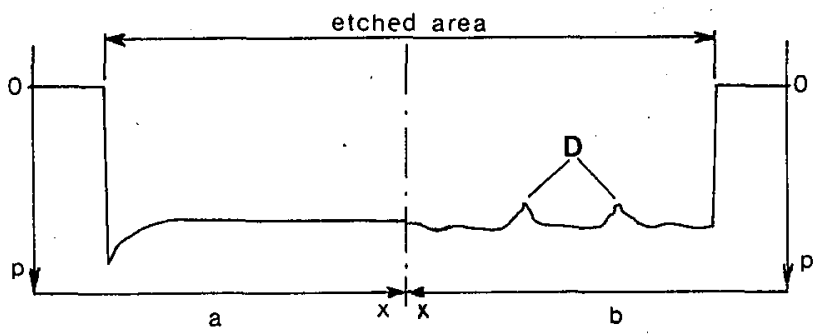

Fig. 1. Surface profiles for: (a) diffusion-limited and (b) defect-selective etching of GaAs. $D$ denotes etch features related to defects, $p$ etch depth, $x$ lateral distance.

should be characterized by a high difference in the etching rates at areas of perfect material compared to the defect sites. More detailed characteristics of different methods of etching of elemental and compound semiconductors can be found in Refs. [1-3].

Since the etching of semiconductors is of an electrochemical nature it is possible to influence the kinetics of the process by an additional supply of carriers. This can be realized either by the application of an external potential or by illuminating the etched surface with light of a wavelength corresponding to the bandgap of the semiconductor. The photogenerated carriers may then contribute to the dissolution of the material and, if some conditions are fulfilled, may considerably increase defect selectivity. This method, called photoetching, has become in the last decade a popular tool for studying defects in III-V materials and is described in detail for GaAs in the next sections of this paper.

\section{Mechanism of selective etching and photoetching}

\subsection{Morphology of etch features on dislocations}

Let us first consider the morphological characteristics of etch features on dislocations which are a major concern in compound semiconductors. Two distinct groups of etch features are formed on dislocations emerging at a surface, namely etch pits and etch hillocks. The rules of formation of etch pits are relatively well recognized and understood for different types of materials [4]. It is a commonly accepted opinion that the energy accumulated around the dislocation line due to lattice distortion and strain field is the driving force for nucleation of pits. Apart 
from this thermodynamic-related condition, the formation of visible etch pits requires a proper ratio of the dissolution rates at the dislocation $\left(V_{D}\right)$, defect-free surface $\left(V_{\mathrm{p}}\right)$ and horizontal step movement $\left(V_{s}\right)$, see Fig. 2(a), i.e. it is dependent on the kinetics of dissolution. The morphology of pits depends furthermore on the
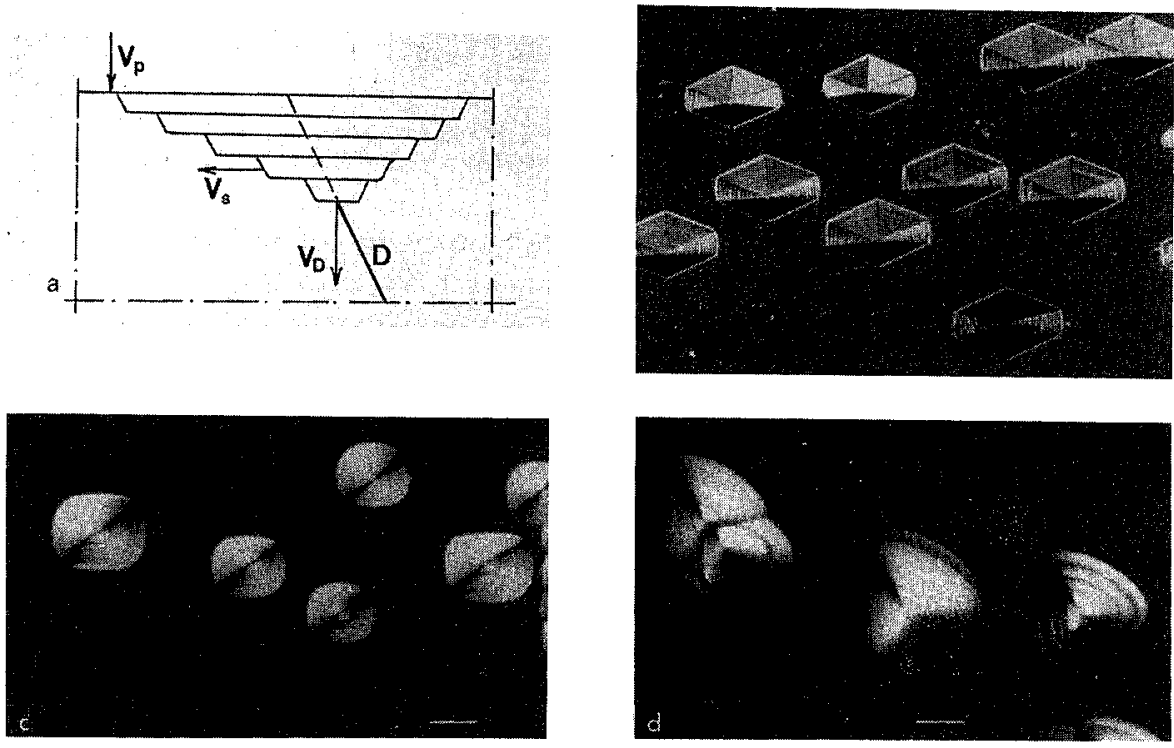

Fig. 2. (a) A schematic representation of etch pit (cross section) formed on dislocation $(D)$ intersecting the etched surface. (b-d) Differential interference contrast (DIC) images of preferentially etched: (b) (001) surface of GaAs in molten $\mathrm{KOH}$ at $440^{\circ} \mathrm{C}$ [5], (c) (001) surface of InP in $\mathrm{HNO}_{3} / \mathrm{HBr}$ etchant [6], (d) $\{111\} \mathrm{Ga}$ in $\mathrm{CrO}_{3} / \mathrm{HCl}$ solution [7]. Markers represent $20 \mu \mathrm{m}$.

crystallographic orientation of the etched surface, the inclination of the dislocation line to the etched surface and the chemistry of the semiconductor-etchant system. For III-V materials there is a large number of etching systems which produce well developed preferential (crystallography-dependent) pits. Figure 2(b-d) illustrates etch pits on $\{111\} \mathrm{Ga}$ surface of GaAs and (001) surfaces of GaAs and InP.

The second group of etch features covers non-crystallographic etch hillocks or ridges, the shape of which depends mainly on the position of dislocations with respect to the surface and on the etch depth. These types of features are formed on dislocations during etching of compound semiconductors in the dark in Redox etching systems, i.e. in solutions containing oxidizing and reducing components. It was shown for the GaAs- $\left(\mathrm{CrO}_{3}-\mathrm{HF}-\mathrm{H}_{2} \mathrm{O}\right)$ system that in the kinetically controlled solutions, the surface coverage by the passivating film is high and depends upon local deformation of the lattice (e.g. dislocation outcrops) [8]. This results in a local decrease of etch rate and in the formation of hillocks. Figure 3 shows characteristic etch pattern obtained after etching in the dark of $n$-type $\mathrm{GaAs}$ in the $\mathrm{CrO}_{3}-\mathrm{HF}$ aqueous solution. The protrusion $(P)$ marking the position of the outcrop of the 

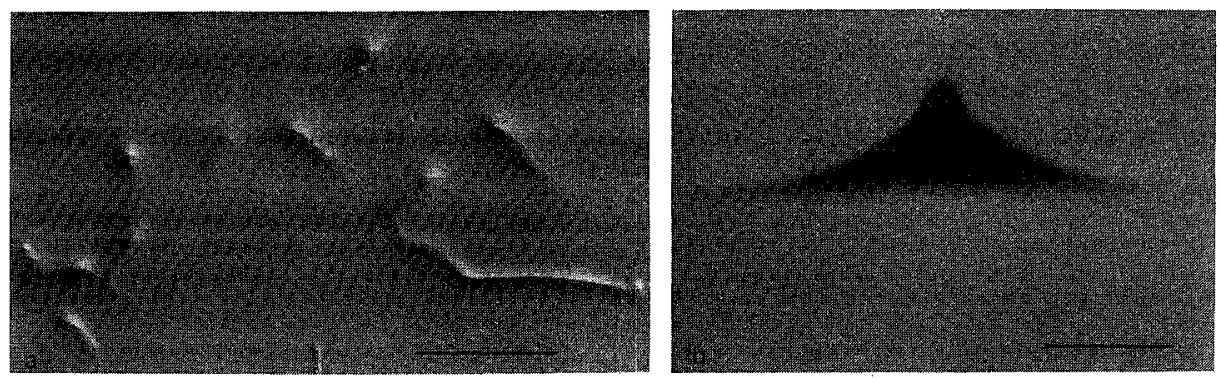

Fig. 3. Etch hillocks and ridges formed on dislocations in $n$-type GaAs during dark etching in $\mathrm{CrO}_{3} / \mathrm{HF}$ solution. (a) DIC image, marker represent $50 \mu \mathrm{m}$. (b) Scanning electron microscope (SEM) image, specimen tilt $80^{\circ}$, marker represent $2 \mu \mathrm{m}$.

dislocation at the surface, clearly visible in SEM image (Fig. 3(b)), usually cannot be recognized on the DIC images (Fig. 3(a)) because of its submicron size.

Selective etching, independently on whether pits or hillocks are formed, is an indirect method, i.e. the etch features are formed due to the presence of defects, but the defects themselves are not directly observed. Considering this fact, the formation of hillocks might be advantageous over the formation of pits, because the defects are preserved in the etched material and a subsequent calibration with any direct physical or structural method is possible.

\subsection{Surface mechanisms of selective etching of GaAs}

The mechanisms involved in local differentiation of the dissolution rate at the defect sites and on the perfect lattice depend on the chemistry of the semiconductor-etchant system. Good defect revealing is usually obtained during electroless etching of compound semiconductors in Redox etching systems. One of the most popular systems of this type used for selective etching of GaAs is based on $\mathrm{CrO}_{3}-\mathrm{HF}$ aqueous solutions. Originally it was used together with addition of $\mathrm{AgNO}_{3}$ [9] (etchant called $\mathrm{AB}$ ). Modifications introduced subsequently showed that better control of surface reactions and higher defect-selectivity can be obtained when the $\mathrm{AB}$ etchant is used in diluted form together with illumination $[10,11]$. It appeared also that silver ions do not influence the etching kinetics of the diluted $\mathrm{AB}$ solutions [10]. Consequently the three component etching system was introduced, called DSL (Diluted Sirtl solutions used with Light). Both phenomenology of the DSL system [12-14] and mechanism of dissolution of GaAs $[8,16]$ were described in detail. More recent studies of different types of inhomogeneities of GaAs crystals using the DS(L) and other structural methods [17-23] allow one to formulate some principles of formation of defect-related etch features. These are summarized below.

(i) Only etchants in the composition range from the $\mathrm{CrO}_{3}-\mathrm{HF}-\mathrm{H}_{2} \mathrm{O}$ ternary diagram, in which the etching is kinetically controlled are suitable for defect revealing. This is range $I$ and $A$ according to the notation in [12] and [8], respectively. 
In this range the concentration of $\mathrm{HF}$ is relatively low, therefore the surface coverage by the passivating layer containing chromium complexes is high. Consequently selectivity on defect sites is also high. Solutions with other compositions produce false etch features, such as microroughness or hillocks not related to the defects [13].

(ii) From the model of surface reactions on GaAs in the $\mathrm{CrO}_{3}-\mathrm{HF}$ solutions it follows that in order to dissolve one GaAs molecule six holes are required. They are injected during passivation reaction from active $\mathrm{Cr}$ species and can be supplied from external sources, for instance as photogenerated carriers. The effectiveness of this last process must depend on the type of conductivity because band bending at the semiconductor surface in contact with etching solution depends also on the type of material. In $n$-type semiconductors the upward band bending is strong and the electron-hole pairs generated by light are immediately separated within the surface depletion layer. Consequently the photogenerated holes can contribute to the reactions. In $p$-type material the bands are nearly flat and the photogenerated carriers recombine effectively in the light absorption region; no influence of illumination on the etch rate is observed.

(iii) It was demonstrated that the DSL photoetching is very effective in revealing extended chemical inhomogeneities viz. growth striations in all types of GaAs (p-, $n$-type and semi-insulating $[14,17,21])$. The mechanisms of differentiation of the etch rates across these inhomogeneous areas are, however, different for each type of material.

In $n$-type GaAs, from a calibration of the DSL etched surfaces with EBIC measurements [17], a quantitative relationship was established between the photo-etch depth $(E)$ and the doping level $(\mathrm{N})$ for a mixed $4 n / n^{+}$system: $E=$ $(-1 / \beta) \times \ln N / N_{0}$, where $N_{0}$ is carrier concentration for the reference etch depth and $\beta$ denotes slope of the $N=f(E)$ exponential plot. This relationship was further explained using a variable width $\left(w_{s c}\right)$ of surface depleted layer which depends on the doping level according to: $N \propto w_{s c}$. Since a higher doping level causes the formation of a narrower surface depletion layer, there are less photogenerated holes for surface reactions, i.e. the etch rate on more doped $\left(n^{+}\right)$regions is smaller compared to regions of lower doping level $(n)$ [23].

In $p / p^{+}$GaAs system, during electroless etching a constant mixed potential $\left(V_{\text {mix }}\right)$ is established at the whole semiconductor surface [8]. Since the rest potentials for the separate $p$ and $p^{+}$materials would be different, also the partial currents and corresponding etch rates are different on $p / p^{+}$areas, being lower for $p$ regions $[8,14]$. This effect, called cathodic protection, accounts for the revealing of the growth striations and can contribute to the formation of complex etch features. on extended Cottrell atmospheres.

In semi-insulating GaAs the remarkable differences of the rate of the DSL photoetching across the growth striations can be attributed to the variable concentration of deep, As-related electron-hole traps which influence recombination of photogenerated carriers [21].

(iv) During dark DS etching the dislocations are revealed as hillocks independently on the electrical type of the material due to the reason given in Sect. 2.1. On the contrary, the DSL photoetching yields a large variety of etch features 
on dislocations depending on the degree/type of decoration and type of the examined material (except for $p$-type GaAs where no difference between the DS and the DSL etching effect could have been so far discerned). In this case the recombinative properties of Cottrell atmospheres decide the shape of dislocation-related etch features. The most clear evidence of the role of light was registered after photoetching of $n$-type $\mathrm{Si}$-doped GaAs grown from As- and Ga-rich melts [18-20, 22] and is summarized in Fig. 4. Hillocks are formed on the Cottrell atmospheres
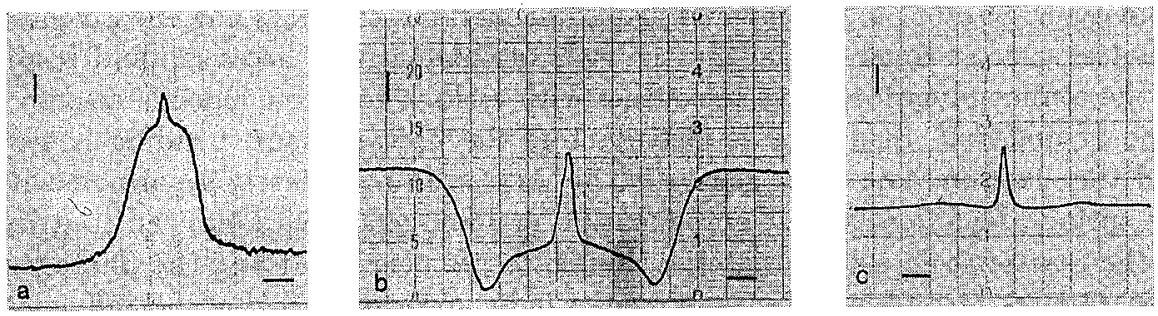

Fig. 4. Surface profiles across the dislocation-related features formed during the DSL photoetching $(\mathrm{a}, \mathrm{b})$ and the dark DS etching (c) in $n$-type GaAs grown from As-rich (a) and Ga-rich melt $(\mathrm{b}, \mathrm{c})$. Horizontal markers represent $10 \mu \mathrm{m}$, vertical $0.1 \mu \mathrm{m}$.

containing recombinative defects (Fig. 4(a)) that result in a local decrease of density of photogenerated carriers (holes). The effect of gettering by the dislocation of $n$-type dopant to form local $n^{+}$area may additionally contribute to the formation of hillocks by a decrease of $w_{s c}$, as was discussed earlier in this section. When the Cottrell atmospheres are dominated by acceptor-type defects, with a simultaneous decrease of $n$-type doping [20,22], the amount of holes increases locally and the atmospheres are etched at a higher rate than the matrix (Fig. 4(b)). For comparison, Fig. 4(c) shows characteristic shape of etch figure obtained in both types of materials during dark DS etching. It is important to note that in both materials the recombination at the dislocations themselves is very effective and leads to the formation of similar protrutions $(P)$ independently on the behaviour of the surrounding atmospheres.

More complex etch features on dislocations in semi-insulating undoped GaAs are discussed in the next Section.

\section{Special topics}

\subsection{Nature and origin of complex defects in SI GaAs}

In semi-insulating undoped GaAs grown by Liquid Encapsulated Czochralski method under low thermal gradient conditions, the dislocations form cell patterns, with uniform dislocation density distribution on a macroscale, leading to the conclusion that the thermal stress model of formation of dislocations is not adequate in this case [24]. At the same time a very high degree of chemical inhomogeneity in a microscale (across the dislocation cell walls) was observed in this type of GaAs 
$[14,24-26]$. This effect is demonstrated by surface profiling on samples after the DSL photoetching (Fig. 5). The explanation of the peculiar DSL etch features
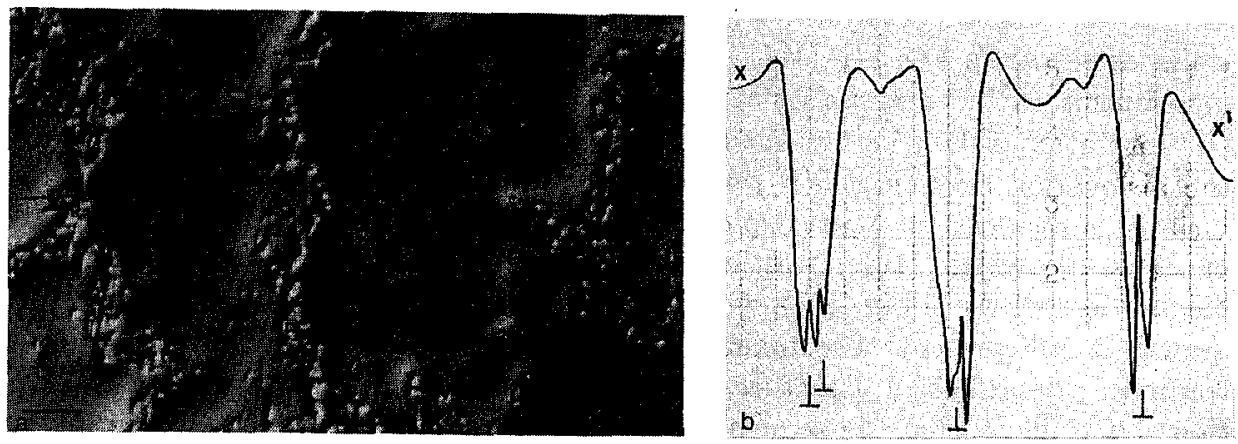

Fig. 5. Surface morphology of SI undoped as-grown GaAs after DSL photoetching, DIC image (a) and surface profiling along $x-x^{\prime}$ line (b). Markers represent $100 \mu \mathrm{m}$. Symbol $\perp$ points out position of dislocations forming cell walls.

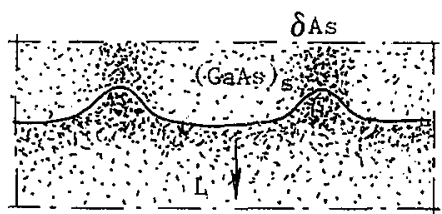

(a)

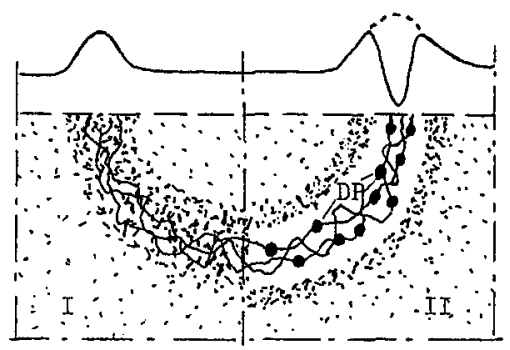

Fig. 6. (a) A schematic representation of the solid-liquid interface during crystallization of GaAs under the conditions favouring constitutional supercooling. (b) A cross-section through a dislocation cell before (I) and after (II) formation of arsenic DP. The dots represent excess of arsenic both in $\mathrm{L}$ and $\mathrm{S}$ phases. Upper part of (b) shows the hypothetical distribution of As and related defects.

across the dislocation cell walls is based on the assumption that the excess of arsenic during the growth of GaAs from As-rich melt behaves like an impurity with the distribution coefficient $\left(k_{0}\right)$ less than unity, and that constitutional supercooling, which is favoured during low thermal gradient growth, is the reason for the formation of the cell structure in undoped crystals [24, 27, 28]. The suggested sequence of events is as follows: local fluctuations (e.g. increase) of the excess of arsenic in the boundary layer before the growing front result in local decrease of freezing temperature and breaking of the planar growth front. This causes inhomogeneous incorporation of the excessive arsenic $\partial A$ s according to the draft of Fig. 6(a). The zones enriched in As become the favoured sites for nucleation of 
dislocations which then may expand on cooling to form an entangled network usually recognized inside the cell walls, Fig. 6(b)(I). During further cooling, when the temperature becomes lower than the equilibrium temperature at the retrograde solidus line, arsenic precipitates (DP) are formed on the already existing dislocations, as shown in Fig. 6(b)(II). The upper part of Fig. 6(b) shows a hypothetical distribution of the excess of As across the dislocation cell walls before (I) and after (II) formation of DP. Using this model the variations of the photoetch rate across the dislocation cells (Fig. 5(b)) can be explained: the highest etch rate is in the vicinity of dislocations (area depleted of As-related recombinative defects, usually of $10-50 \mu \mathrm{m}$ width), the lowest etch rate is in the next neighbouring matrix, indicated by arrows in Fig. 5(b), where the remainder of the $\partial$ As introduced during growth is still present. The main difference between this model and the opinion commonly described in literature on the origin of Cottrell atmospheres of dislocation cell walls is then the sequence of events; it is assumed that gettering of As (and related defects e.g. EL2) on dislocations occurs during post-growth cooling [29-32], while in this model a local agglomeration of native defects constitutes the primary structural feature. An additional implication of the present model is that in the vicinity of dislocations a narrow depleted area of EL2 defects might be expected. This conclusion is seemingly in contradiction to the usually reported increase in EL2 concentration at the cell walls [33, 34], which might result from relatively poor spatial resolution of the near-infrared absorption method $(80 \mu \mathrm{m})$. The typical width of the Cottrell atmosphere at the dislocation cell walls is in the range of $100-200 \mu \mathrm{m}$ and that of depleted zones, due to As precipitation, is below $50 \mu \mathrm{m}$ (see Fig. 5). However, in the recently grown crystals of $3 \|$ diameter [36] exceptionally large cells were revealed by the DSL method, with cell wall thickness up to $400 \mu \mathrm{m}$ [36]. In the same material for the first time a decrease in EL2 concentration was recorded inside so thick a cell wall (see Fig. I in [35]), being in agreement with the above reasoning.

This high degree of micro-inhomogeneity of the as-grown undoped SI GaAs can be removed by ingot or wafer annealing, which has become already a standard specification for commercially available substrates. It is known that the homogenization of GaAs is a consequence of two competitive diffusive processes that occur during annealing, namely (a) formation of As precipitates on dislocations (DP) and in the matrix (MP) and (b) formation of deep donor EL2 defects [29, 37-39]. It was also demonstrated that DSL photoetching combined with local etch rate measurements is an ultra-sensitive tool for recognizing these subtle structural changes [26]. Figure 7 demonstrates that both precipitates (DP, MP) and changes in the distribution of deep recombinative levels are clearly revealed by photoetching. The precipitates decorating dislocations are the reason of formation of large shallow pits on dislocation-related hillocks and the matrix precipitates are revealed as similar shallow pits but with a smaller size (Fig. 7(c)). The MP form spherical "bubbles" or spheroids in the cell interiors. Consequently, the photoetch rate in the vicinity of dislocations forming cell walls and inside the cells, where the MP are present, is increased, see Fig. 7(b). In Fig. 7 the spheroids of the MP were present, therefore the etch rate increased in the shell of the spheroids but not in the centre. Such 3D distribution of the MP has been well-documented by previous 

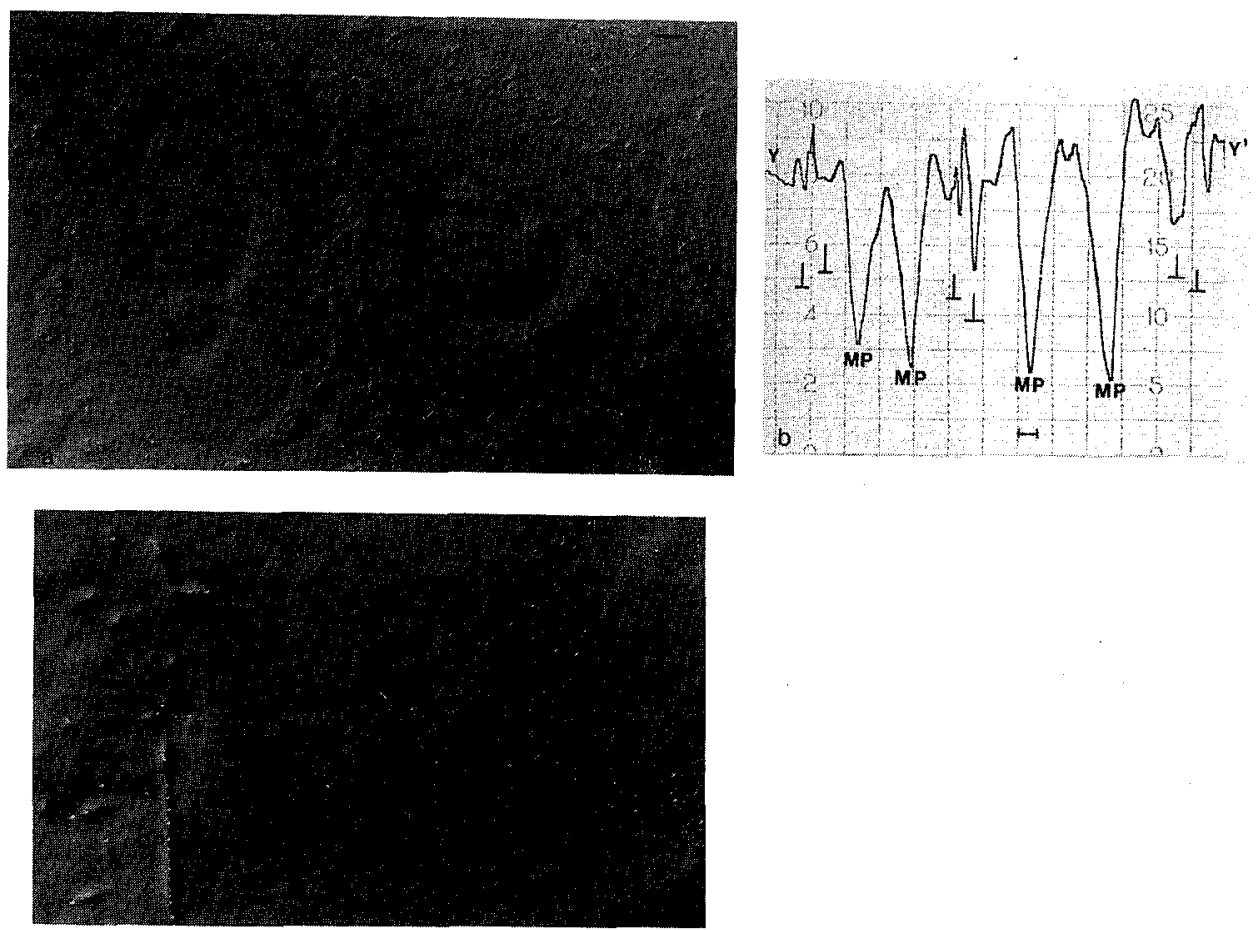

Fig. 7. Surface morphology of SI undoped annealed GaAs after DSL photoetching, DIC image (a, c) and surface profiling along $y-y^{\prime}$ line (b). Markers represent $50 \mu \mathrm{m}$. DP denots arsenic precipitates decorating dislocations at the cell walls, MP arsenic precipitates in the dislocation-free matrix. Symbol $\perp$ points out position of dislocations.

studies using spatial Laser Scattering Tomography procedure [26, 40].

\subsection{Revealing of "glide" dislocations by the DSL photoetching}

One of the most fascinating but as yet unexplored possibilities of the DSL method is its ability to reveal the traces of dislocations which move during post-growth cooling, due to thermal stresses [14, 25, 41]. During movement the dislocations interact with the point defects and leave behind deep nonradiative centres, as was recognized by high spatial resolution photoluminescence $[19,22]$. These traces are etched slower under illumination due to recombination of photogenerated carriers. The possibility to define the glide system of moved dislocations by projective etching $[25,41]$ seems to be especially atractive. In order to illustrate this etching procedure Fig. 8 shows an $n$-type GaAs sample after projective etching (shallow DSL, deep DS and repeated shallow DSL). From the analysis of the crystallography of the etched (001) GaAs surface in this figure it follows that the dislocation changed several times $\{111\}\langle 110\rangle$ glide system and twice moved in $\{100\}\langle 100\rangle$ or $\{100\}\langle 110\rangle$ systems. "Bending" of some segments of the trace (marked by arrow in 


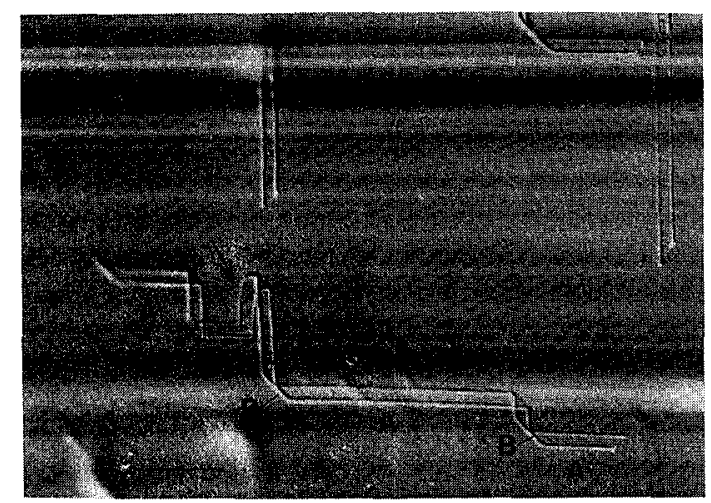

Fig. 8. Dislocations in $n$-type GaAs moved by thermal stresses arising during post-growth cooling, revealed by projective etching [41]. "A" denotes $\{111\}\langle 110\rangle$ and "B" $\{100\}\langle 100\rangle$ glide systems. Marker represents $100 \mu \mathrm{m}$.

Fig. 8) supports the concept of simultaneous glide/climb mechanism of movement of dislocations, as suggested in [42] and recently discussed in [22].

\section{Conclusions}

1. Etching of $\mathrm{GaAs}$ in the $\mathrm{CrO}_{3}-\mathrm{HF}$ aqueous solutions in a kinetically controlled range of compositions proceeds via a Redox mechanism and constitutes a very sensitive technique for revealing defects.

2. The use of light during etching considerably increases the sensitivity of etching, i.e. decreases the minimum etch depth required to distinguish defect-related etch features. Such shallow photoetching is advisable when subtle structural features have to be examined.

3. Structural observations after etching of SI and $n$-type GaAs indicate that in the dark the stress field around dislocations is responsible for formation of the etch hillocks, while under illumination all the factors that influence the number of holes required for surface reactions influence the complex shape of etch features.

\section{Acknowledgments}

This work was financially supported by the EEC contract \# SC 1/0247. 


\section{References}

[1] D.J. Stirland, B.W. Straughan, Thin Solid Films 31, 139 (1976).

[2] D.C. Miller, G.A. Rozgonyi, in Handbook on Semiconductors, Ed. S.B. Keller, North-Holland, Amsterdam, 1980, Vol. 3, p. 218.

[3] S.D. Mukherjee, D.W. Woodard in Gallium Arsenide, Eds. M.J. Howes, D.V. Morgan, Wiley, Chichester 1985, p. 119.

[4] K. Sangwal, Etching of Crystals, North-Holland, Amsterdam 1987.

[5] J.G. Grabmaier, C.B. Watson, Phys. Status Solidi 32, K13 (1969).

[6] S.N.G. Chu, C.M. Jodlauk, A.A. Ballman, J. Electrochem. Soc. 129, 352 (1982).

[7] J. van de Ven, A.F. Laurens, J.L. Weyher, L.J. Giling, Chemtronics 1, 19 (1986).

[8] J. van de Ven, J.L. Weyher, J.E.A.M. van den Meerakker, J.J. Kelly, J. Electrochem. Soc. 133, 799 (1986).

[9] M.S. Abrahams, C.J. Buiocchi, J. Appl. Phys. 36, 2855 (1965).

[10] T. Saitoh, S. Matsubara, S. Minagawa, J. Electrochem. Soc. 122, 670 (1975).

[11] A. Munoz-Yague; M. Bafleur, J. Crystal Growth 53, 239 (1981).

[12] J.L. Weyher, J. van de Ven, ibid. 63, 285 (1983).

[13] J.L. Weyher, W. van Enckevort, ibid. 63, 292 (1983).

[14] J.L. Weyher, J. van de Ven, ibid. 78, 191 (1986).

[15] J. van de Ven, J.E.A.M. van den Meerakker, J.J. Kelly, J. Electrochem. Soc. 132, 3020 (1985).

[16] J.J. Kelly, J. van de Ven, J.E.A.M. van den Meerakker, ibid. 132, 3026 (1985).

[17] C. Frigeri, J.L. Weyher, L. Zanotti, ibid. 136, 162 (1989).

[18] C. Frigeri, J.L. Weyher, J. Appl. Phys. 65, 4646 (1989).

[19] E.P. Visser, P.J. van der Wel, J.L. Weyher, L.J. Giling, ibid. 68, 4242 (1990).

[20] J.L.Weyher, C. Frigeri, P.J. van der Wel, J. Crystal Growth 103, 46 (1990).

[21] J.L. Weyher, P.J. van der Wel, G. Frigerio, C. Mucchino, in Proc. 6th Conf. on SI III-V Mat., Eds. A. Milnes, C. Miner, Hilger, Bristol 1990, p. 161.

[22] J.L. Weyher, P.J. van der Wel, C. Frigeri, in Proc. DRIP-IV Conf., Wilmslow (UK) 1991, paper accepted.

[23] C. Frigeri, J.L. Weyher, L. Zanotti, Mat. Res. Soc. Symp. Proc., Vol. 138, Eds. B.C. Larson, M. Ruhle, D.N. Seidman, MRS, Pittsburgh, 1989, p. 527.

[24] J.L. Weyher, Le Si Dang, E.P. Visser, Inst. Phys. Conf. Ser. No. 91, 109 (1987).

[25] J.L. Weyher, J.L. Giling, Proc. DRIP-I Symp., Ed. J.P. Fillard, Elsevier, Amsterdam 1986, p. 63.

[26] J.L. Weyher, P. Gall, Le Si Dang, J.P. Fillard, J. Bonnafe, H. Rufer, M. Baumgartner, K. Lohnert, in Proc. DRIP-IV Conf., Wilmslow (UK) 1991, paper accepted.

[27] J.L. Weyher, in Proc. 5th Conf. on SI III-V Mat., Eds. G. Grossmann, L. Ledebo, Hilger, Bristol 1988, p. 499. 
[28] T. Figielski, in Proc. 8th Int. School on Defects in Crystals, Szczyrk (Poland) 1988, Ed. E. Mizera, World Scientific, Singapore 1988, p. 379.

[29] B.-T. Lee, E.D. Bourret, R. Gronsky, In-Shik Park, J. Appl. Phys. 65, 1030 (1989).

[30] M.R. Brozel, I. Grant, R.M. Ware, D.J. Stirland, M.S. Skolnick, J. Appl. Phys. 56, 1109 (1984).

[31] P. Dobrilla, J.S. Blakemore, J. Appl. Phys. 61, 1442 (1987).

[32] E. Molva, Ph. Bunod, A. Chabli, A. Lombardot, S. Dubois, F. Bertin, J. Crystal Growth 103, 91 (1990).

[33] A. Winnacker, F.X. Zach, ibid. 103, 275 (1990).

[34] S. Clark, M.R. Brozel, D.J. Stirland, ibid. 103, 102 (1990).

[35] M. Baumgartner, G. Nagel, K. Lohnert, in Proc. 6th Conf. on S-I III-V Mat., Eds. A.G. Milnes, C. Miner, Hilger, Bristol 1990, p. 225.

[36] J.L. Weyher, unpublished results.

[37] T. Inada, Y. Otoki, K. Ohata, S. Taharasako, S. Kuma, J. Crystal Growth 96, 327 (1989).

[38] Y. Otoki, M. Watanabe, T. Inada, S. Kuma, ibid. 103, 85 (1990).

[39] T. Inada, Y. Otoki, S. Kuma, ibid. 102, 915 (1990).

[40] J.P. Fillard, P. Gall, J.L. Weyher, M. Asgarinia, P.C. Montgomery, in Proc. 5th Conf. on S-I III-V Mat., Eds. G. Grossmann, Ledebo, Hilger, Bristol 1988, p. 537.

[41] J.L. Weyher, in Proc. 1984 Meeting on Caratterizzazione Anal.-Strutturale Mat., Eds. S. Carra, C. Ghezzi, P.G. Merli, C. Paorici, Tecnografica, Parma 1984, p. 1.

[42] T. Figielski, Appl. Phys. A 36, 217 (1985). 